\title{
Elas podem se machucar: As Lutas no combate ao preconceito de gênero na Educação Física Escolar
}

\author{
They can get hurted: Struggles to combat gender prejudice in School Physical Education \\ Pueden ser heridas: Las peleas en la Lucha contra los prejuicios de género en la Educación Física
}

Escolar

Recebido: 13/02/2021 | Revisado: 21/02/2021 | Aceito: 25/02/2021 | Publicado: 04/03/2021

Eder Rodrigo Mariano

ORCID: https://orcid.org/0000-0002-3345-0003

Universidade Federal do Maranhão, Brasil

E-mail: eder.mariano@ufma.br

Francisco Eduardo Lopes da Silva

ORCID: https://orcid.org/0000-0001-8998-6803

Universidade Federal do Maranhão, Brasil E-mail: f.eduardolopes@ hotmail.com

Sérgio Souza

ORCID: https://orcid.org/0000-0003-2633-9654

Universidade Federal do Maranhão, Brasil

E-mail: sergio.souza@ufma.br

Deyvid Tenner de Souza Rizzo

ORCID: https://orcid.org/0000-0002-9622-9816

Universidade. Federal do Mato Grosso do Sul, Brasil

E-mail: deyvidrizzo1@gmail.com

Vitor Alberto Valadas Rosa

ORCID: https://orcid.org/0000-0002-5093-8115

Universidade Lusófona de Humanidades e Tecnologias, Portugal

E-mail: vitor.rosa@ulusofona.pt

Luís Fernandes Monteiro

ORCID: https://orcid.org/0000-0001-8118-5593

Universidade Lusófona de Humanidades e Tecnologias, Portugal

E-mail: p625@ulusofona.pt

\begin{abstract}
Resumo
$\mathrm{Na}$ atualidade, as mulheres ainda são estigmatizadas no âmbito esportivo, principalmente no que se refere a prática das Artes Marciais e Esportes de Combate (AM\&EC). No contexto escolar, estudos científicos que tratam da interface entre Lutas e questões de gênero são escassos. Esta investigação buscou apontar a acepção dos alunos sobre a participação feminina nas aulas de Lutas na Educação Física. Os estudantes do $3^{\circ}$ ano do ensino médio responderam à um questionário semiestruturado, antes e após, serem submetidos a seis encontros que envolviam aulas teóricas e aulas práticas subsequentemente, totalizando 140 minutos, cada encontro. O estudo ocorreu no Centro Educacional Dom Ungarelli, em Pinheiro-MA, numa sala de aula adaptada com Tatame e abrangeu 13 modalidades de Lutas. Os pais autorizaram-nos a participar, assinando o Termo de Consentimento Livre e Esclarecido, sendo excluídos aqueles que não frequentaram $75 \%$ das aulas ou não responderam. Os resultados mostram que, preliminarmente, 150 estudantes que participaram do estudo, 120 consideraram negativa a participação das meninas, pelo risco de se machucarem; apenas 19 julgaram-nas capazes e 11 com direitos iguais aos meninos. Posteriormente, todos aprovaram-nas nas aulas de Lutas, 35 confirmaram a capacidade delas e 60 estudantes passaram a reconhecer como uma prática em que as meninas também tem direito de participar; e destacamos que 55 estudantes perceberam que as Lutas rompem o preconceito de gênero. Portanto, concluímos que o conteúdo Lutas pode ser uma importante ferramenta educacional no combate aos estereótipos e preconceitos.
\end{abstract}

Palavras-chave: Artes marciais; Esportes de combate; Lutas; Educação física escolar; Preconceito; Gênero.

\section{Abstract}

Currently, woman are still stigmatized in the sports field. Mainly, in what refers to the practice of Fighting, Martial Arts and Combat Sports (AM\&EC). In the school context, scientific studies dealing with the interface between struggles and gender issues are scarce. This investigation sought to point out the meaning of student about female participation in classes of Struggles in Physical Education. The students of the 3rd year of high school answered a semi-structured questionnaire, before and after being submitted to six meetings that involved theoretical classes and subsequent practical classes, totaling 140 minutes, each meeting. The study took place at the Dom Ungarelli 
Educational Center, in Pinheiro-MA, in the classroom adapted with fighting mat and covered 13 modalities of Fights. The parents authorized us to participate, by signing the Free and Informed Consent Form (TCLE), excluding those who did not attend $75 \%$ of the class or did not answer the questionnaire. The results show that, preliminary, of the 150 students who participated in the study, 120 considered negative the participation of girls, because of the risk of getting hurt; only 19 judged them capable and 11 with equal rights to boys. Subsequently, all approved them in Fighting classes, 35 confirmed their capacity and 60 students began to recognize it as a practice in which girls also have right to participate; and we emphasize that 55 students acknowledge that the Struggles break the gender prejudice. Therefore, we conclude that the content Fighting/Martial Arts/Combat Sports can be an important educational tool in combating stereotypes and prejudices.

Keywords: Martial arts; Combat sports; Fights; School physical education; Preconception; Genre.

\section{Resumen}

En la actualidad, las mujeres siguen estando estigmatizadas en el ámbito deportivo, principalmente en lo que respecta a la práctica de Luchas, Artes Marciales y Deportes de Combate(AM\&EC). En el contexto escolar, los estudios científicos que aborden la interfaz entre luchas y cuestiones de género son escasos. Esta investigación buscó señalar la percepción de los estudiantes sobre la participación femenina en las clases de Lucha en Educación Física. Los alumnos de $3^{\circ}$ año de bachillerato respondieron un cuestionario semiestructurado, antes y después, siendo sometido a seis reuniones que involucraron clases teóricas y prácticas posteriormente, totalizando 140 minutos, cada reunión. El estudio se llevó a cabo en el Centro Educacional Dom Ungarelli, en Pinheiro-MA, en un aula adaptada con Tatami y cubrió 13 tipos de peleas. Los padres nos autorizaron a participar firmando el Formulario de Consentimiento Informado, excluyendo a aquellos que no asistieron al $75 \%$ de las clases o no respondieron. Los resultados muestran que, de manera preliminar, 150 estudiantes que participaron del estudio, 120 consideraron negativa la participación de las niñas, por el riesgo de lastimarse; solo 19 los juzgaron capaces y 11 con los mismos derechos que los niños. Posteriormente, todos los aprobaron en las clases de Lucha, 35 confirmaron su habilidad y 60 estudiantes comenzaron a reconocerla como una práctica en la que las niñas también tienen derecho a participar; y destacamos que 55 estudiantes se dieron cuenta de que las Luchas rompen el sesgo de género. Por tanto, concluimos que el contenido de Fight puede ser una importante herramienta educativa en la lucha contra los estereotipos y prejuicios.

Palabras clave: Artes marciales; Deportes de combate; Peleas; Educación física escolar; Preconcepción; Género.

\section{Introdução}

Denotadas como "sexo frágil", deliberadas aos afazeres domésticos e destinadas à procriação e aos cuidados com a prole, as mulheres sofreram, exageradamente, as barreiras de um julgamento sexista, impelido por fatores culturais da época (Beauvoir, 1980; Terret, 2006). As limitações impostas foram estruturadas por esses estereótipos, o que, deste modo, representava para a sociedade vigente características contrárias às exigências de prática esportiva. Conforme salienta Felipe (2000), ser simples e discreta eram características intensamente valorizados, possivelmente uma das maiores virtudes nas mulheres e meninas. Desta forma, a educação das mulheres foi estruturada de forma diferenciada, voltada para a sua capacidade procriativa e as considerando como subordinadas.

$\mathrm{Na}$ atualidade, as mulheres ainda são descriminadas em vários setores da sociedade. No âmbito esportivo, o preconceito de gênero se faz presente há décadas, e a história da mulher no esporte é pautada pela subversão. Não obstante, o combate ativo na sociedade e no esporte pela equidade de gênero, se torna, a cada dia, mais efetiva e eficaz (Silva, 2017).

Historicamente, no Brasil, durante a presidência de Getúlio Vargas (1937-1945) e o período da Ditadura Militar (1964-1985), foram marcados, de maneira abusiva, pelas limitações de possiblidades de articulação das mulheres no Esporte, haja vista, o vigor do Decreto-lei 3.199 de 14 de abril de 1941, que assim determinava: “Art. 54. Às mulheres não se permitirá a prática de desportos incompatíveis com as condições de sua natureza, devendo, para este efeito, o Conselho Nacional de Desportos baixar as necessárias instruções às entidades desportivas do país” (Decreto-lei 3.199, 1941).

No final do século XIX e transcorrer do século XX, as mulheres iniciaram suas conquistas por posições mais ativas no Esporte e, aos poucos, engajaram-se numa área, que há muito tempo lhes havia sido negada e pela qual se mostravam intensamente seduzidas (Miragaya, 2007). Por consequência, intensificou-se a promoção de eventos esportivos que repercutiram no aumento do quantitativo de mulheres atletas participantes de modalidades esportivas direcionadas a elas

(Oliveira, 2011). 
Culturalmente, a participação das mulheres nas artes marciais e esportes de combate (AM\&EC) era considerada uma prática anormal, inconveniente e periculosa; ao passo que, para os homens, lhes eram, e ainda são atribuídas as qualidades necessárias para praticá-las, como a virilidade, a coragem e a força. Discurso este, legitimado a partir da perspectiva biológica e adotado como estratégia para manter as mulheres afastadas desta prática esportiva (Santana da Silva, 2019).

Ressaltamos que a inserção efetiva das mulheres nas AM\&EC, em particular nas Lutas, ocorreu de forma tardia. Os registros datam a primeira participação das mulheres na Esgrima em 1924, em Jogos Olímpicos (Mourão \& Sebastião, 2005). No Judô, elas iniciaram seu protagonismo a partir de 1992 (COI, 2016). Em 2000, houve a estreia feminina na modalidade Taekwondo (Pereira \& Carneiro, 2016), e em 2004, a Luta Olímpica - Estilo Livre entrou em cena com a disputa feminina (COI, 2016). Na nobre arte, o Boxe, registrou-se a marcante participação feminina somente no ano de 2012 (Cardoso et al., 2013). Este "considerável atraso" foi justificado no estudo de Jardim (2018) ao mostrar as Lutas como práticas marcadas pelo domínio masculino, e portanto, inadequadas ao corpo frágil, delicado e passivo da mulher.

Por ser um tema contestável, o preconceito de gênero, necessita ser discutido na esfera educacional, especificamente, nas aulas de Educação Física Escolar (EFE), onde encontramos um campo fértil no trato desta temática, em específico, ao eixo temático Lutas, determinado pela Base Nacional Comum Curricular (BNCC), na área de Linguagens (Ministério da Educação, 2015). Como afirmam Lima et al. (2017, p. 437-438): “a luta não é um conteúdo com o fím em si mesmo, ela também deve ser utilizada na abordagem dos temas transversais, já que está diretamente ligada às questões pertinentes ao gênero".

Evidenciamos, na obra de Rosa et al. (2020), a presença frequente do preconceito de gênero contra mulheres/alunas/professoras no âmbito educacional através de declarações ofensivas, tais como: marica, bicha, mulherzinha, afeminado, mulher macho e paraíba; ao passo que, no estudo de Lima et al. (2017, p.438), que tratava do preconceito de gênero entre alunos do nono ano, nas aulas de Educação Física, registrou-se a persistência na pronúncia da frase: “as meninas devem praticar balé e os meninos as lutas", mencionada pelos garotos. Tais atitudes e conotações podem ocorrer em virtude das consequências culturais, relações escolares, ou ainda, da influência familiar (Rosa et al., 2020).

Neste contexto, Costa (2019) compactuou com uma postura bastante adversa diante de tal situação. Ele defendeu o pensamento de que atitudes de preconceito de gênero no ambiente educacional deveriam ser discutidas e abolidas. Outrossim, Rodrigues et al. (2017) alvitrou a possibilidade de se elaborar estratégias para elucidar o papel das Lutas no ambiente escolar e romper com os estereótipos que, em outros momentos, relacionavam tais práticas como inadequadas ao gênero feminino.

Recentemente, alguns estudos problematizaram as relações de gênero e das sexualidades no cotidiano do currículo escolar (Da Silva Barros \& Queiroz, 2020; Miranda \& Dos Reis, 2020; Costa, 2019; So et al., 2018), que culminaram num atual ataque as discussões de gênero no ambiente educacional.

Estudos atuais se propuseram a verificar o efeito de programas de iniciação as lutas em estudantes no contexto escolar (Rodrigues et al., 2017; Silva et al., 2019). A desmistificação das Lutas nas aulas de Educação Física Escolar (EFE) se apresenta como tema emergente (Silva et al., 2020). Firmino e de Souza Ventura (2017) propõe uma análise sistematizada desta temática na busca pela emancipação da mulher em diferentes modalidades de Lutas. Os autores Silva et al. (2020) compreendem as Lutas como campo afetivo social que estabelece vínculo entre os envolvidos, por meio de ações e reações durante o embate. Neste pensamento, os participantes adotam uma postura de confronto, que de forma controversa, promove a socialização e incita atitudes de perseverança, respeito e determinação. Lima et al. (2017) consideram as Lutas como uma excelente ferramenta no trato de questões de gênero, na educação formal e informal, na contemporaneidade.

Todavia, na interface entre lutas e gênero, no contexto da EFE, pouco se investigou e se publicou na literatura científica. Lima et al. (2017) reforçam a carência de pesquisas e novos apontamentos desta temática, principalmente, na esfera educacional.

Nesta perspectiva, este artigo tem como objetivo verificar a concepção dos alunos a respeito do preconceito de gênero 
diante da participação de meninas nas aulas de Lutas; buscou-se ainda, apontar, se as Lutas promovem inclusão ou a exclusão de alunos, durante a participação em um bloco de atividades envolvendo diferentes modalidades de Lutas, no ensino médio.

\subsection{Gênero, Esporte e Sociedade}

Quando problematizamos as questões de gênero na sociedade, constatamos conexões com evidências históricas, culturais, sociais e legislativas que se constituíram desde a determinação daquilo que "é de menino ou de menina" ao longo da infância, até o preconceito contra a participação das mulheres nas AM\&EC, tanto no ambiente educacional formal como no informal, evidenciados na atualidade.

Com o ressurgimento dos Jogos Olímpicos (JO), promovidos por Pierre de Fredy, o Barão de Coubertin, foi criado o órgão que passou a regulamentá-los: o Comitê Olímpico Internacional (COI) (Firmino \& De Souza Ventura, 2017). Porém, para as mulheres foi mantida a proibição delas em participação de eventos esportivos, desde os Jogos da Antiguidade, sendo então, abdicadas de exercerem sua cidadania.

Contudo, nos JO de Atenas em 1896, Stamata Revith, mulher grega de aproximadamente 30 anos de idade, tentou realizar sua inscrição na prova de Atletismo, mas teve seu pedido indeferido; tendo que participar de modo não oficial do lado externo do estádio, o que impulsionou, mesmo que de modo isolado, iniciativas em prol de seus direitos de igualdade (Firmino, 2014).

Um momento político e histórico marcante na trajetória das mulheres em busca dos seus diretos, foi a passeata das sufragistas, realizada no ano de 1912, em Nova York, no qual mulheres de distintas classes sociais se reuniram em uma passeata com objetivo de garantir o direito ao voto. Direito este, consumado em 1920 (Firmino \& De Souza Ventura, 2017). Tal fato caracteriza um período de mudanças na atitude das mulheres que, a partir de então, assumiram uma nova postura na luta por seus direitos no âmbito social.

Enquanto que, no Brasil, o governo executava a implantação de Decretos de Lei e imposições políticas, registrados entre as décadas de trinta e oitenta, consolidando a regulamentação do Esporte Nacional que, em 1965, determinou o vigor da deliberação $n^{\circ} 07$ do Conselho Nacional de Desportos (CND), proibindo a mulher de praticar Lutas de qualquer natureza, Futebol, Futebol de Salão, Futebol de Praia, Pólo-Aquático, Pólo, Rugby, Halterofilismo e Baseball (Conselho Nacional de Desportos, 1965). Ressaltamos neste ponto, a configuração de uma barreira legislativa, além das barreiras culturais. A própria legislação fragiliza as mulheres e as classificavam como incompatíveis para a prática desportiva, inclusive as AM\&EC.

Somente após mais uma década, foi desmembrada a deliberação $n^{\circ} 7$ de 1965 , vigorando assim a deliberação $n^{\circ} 10$ de 1979, concedendo legalmente às mulheres a permissão para praticar qualquer modalidade esportiva, embora houvesse algumas limitações, como a condição da instituição internacional da modalidade, realizar campeonatos e torneios oficiais femininos e misto. Caso contrário, teria que ser requerida uma permissão ao Conselho Nacional de Desportos, para a modalidade em específico (Decreto-lei nº 89.406, 1984).

Após longos períodos de subversões, em 1900, foi oficializada a participação das mulheres no Tênis e no Golfe, visto que, para a sociedade vigente, representava uma modalidade de esporte sem contato físico, com menores riscos de lesões e possibilitava ao público apreciar a beleza e delicadeza motora das mulheres durante as partidas. Este fato, apesar de expressar uma compreensão limitada; foi favorável à emancipação das mulheres no esporte (Rubio \& Simões, 1999).

No Atletismo, a história de Katharine Switzer, maratonista, é uma grande evidência do preconceito de gênero e da luta pela sua superação. Ela foi a primeira mulher a correr oficialmente a "Corrida Boston", em 1967, e a quebrar o paradigma de mulher masculinizada por praticar tal modalidade, determinada para homens. Sua atitude de coragem e determinação repercutiu no mundo esportivo e incentivou inúmeras mulheres a superarem e a combaterem o preconceito de gênero através do esporte (Lins et al., 2016). 
A Esgrima, que até o século XVIII, era considerada uma atividade bélica destinada ao duelo entre homens e praticada com enorme veemência entre eles (Alves, 2019), foi proibida para o gênero feminino, em virtude da agressividade que representava. No início do século XIX, a modalidade passou a ser oficialmente praticada por mulheres, chegando aos Jogos Olímpicos á partir de 1924 e disseminada a todo público feminino mundial (Mourão \& Sebastião, 2005).

No Brasil, muitas mulheres iniciaram sua busca pela independência financeira e autonomia pessoal trabalhando no comércio, em bancas de rua, açougues e mercados. Entretanto, elas sofriam frequentes tentativas de violência e ameaças. Neste cenário, surgiram as primeiras menções sobre a participação de mulheres em grupos de Capoeira. A partir deste momento, elas passaram a ser estereotipadas pela sociedade como mulheres violentas e arruaceiras, confirmando assim, o preconceito de gênero de caráter cultural que limitou, e ainda limita o público feminino a aderir em diversas áreas de atuação (Oliveira \& Leal, 2009).

Nos anos seguintes percebeu-se uma vagarosa e escassa progressão na participação das mulheres nas AM\&EC, em detrimento a hegemonia e a supervalorização do gênero masculino nas modalidades de combate (Leite et al., 2017).

Neste ínterim, surge uma personagem emblemática, Valdelice Santos de Jesus "Mestra Jararaca”. Em 2001, ela foi reconhecida como a primeira mulher mestra em Capoeira, e tal fato repercutiu no surgimento de uma personalidade feminina ativa na sociedade, com o propósito de combater a discriminação e a desvalorização da mulher na sociedade fortalecendo sobremaneira a autoafirmação da mulher e seu valor na sociedade (Ferreira, 2016).

Ainda hoje, percebemos que algumas práticas de AM\&EC continuam restritas ou proibidas ao público feminino, como é o caso do Sumô, a Arte Marcial mais reverenciada no Japão, local onde as mulheres são oficialmente proibidas de praticá-lo, pois, para os padrões que o povo ali ostenta, isto representaria “o fim do Sumô” (Ledur et al., 2018).

Na prática do Boxe, as menções revelam que as qualidades anatômicas dos corpos determinavam os direitos, deveres e possibilidades de movimentação dentro do embate (Louro, 2018). A rotulação de gênero à mulher praticante de Boxe reflete o efeito de um olhar midiático discriminatório, por considerarem uma prática violenta e bárbara com eminentes riscos à integridade física da mulher. Infelizmente, o Boxe possui uma hegemonia masculina e uma tardia oficialização da participação feminina, fato que ocorreu somente em 2012 (Cardoso et al., 2013).

Ao tratarmos das Artes Marciais Mistas (MMA) no remetemos a Jardim (2018) que as compreende como um conjunto de técnicas de diferentes modalidades de combate, caracterizada por uma prática violenta e agressiva que oferece considerável risco à saúde do praticante, principalmente, quando se trata de mulheres. Contudo, Silveira e Vaz (2016) sugerem que o preconceito frente às mulheres se revela, não pelas capacidades esportivas, mas pelos requisitos femininos heteronormativos.

Em aversão a tais pensamentos, salientamos a visão Santana da Silva (2019) ao atribuir a inserção e valorização das mulheres nas Lutas à expansão do MMA, que por sua vez, foi e é propagado por meio de eventos de grande magnitude midiática, como o Pride Fighting Championship, fundado em 1997, no Japão; o Cage Warriors Fighting Championship, criado na Europa, em 2001; o Jungle Fight Championship, originado no estado do Amazonas, Brasil, em 2006; e o Ultimate Fighting Championship (UFC), nascido em 1993 nos Estados Unidos e reestruturado em 2001, que atualmente, é a maior promotora de eventos de MMA em todos os continentes. Neste "campo de batalha", as mulheres estão conquistando e ampliando seu espaço e reconhecimento, além de deixarem um legado na história das AM\&EC construindo a imagem de mulheres aguerridas, versáteis, determinadas e corajosas (Fernandes, 2015).

Ao romperem as fronteiras da rejeição e da intolerância, as mulheres afrontam o estigma de fragilidade e obediência imposto pela sociedade e abrem novos caminhos e possibilidades encorajando outras ações de combate ao preconceito de gênero, fortalecendo assim, a efetivação de seus direitos (Camargo \& Kessler, 2017). 


\subsection{Lutas, EFE e Preconceito de Gênero: interface em questão}

O entendimento tendencioso de que existe uma divisão das práticas esportivas em masculinas" ou "femininas" pode ter como consequência negativa, atitudes de desvalorização e falta de apoio a determinadas modalidades, como nos casos das AM\&EC quando realizado por mulheres, ou da Ginástica Artística, do Voleibol ou da Dança, quando desempenhados pelo homem (Do Prado et al., 2016). Em circunstâncias mais extremas tais posicionamentos podem se tornar hostis, manifestando como resposta o preconceito de gênero em relação ao que é" normal" e "anormal".

A escola, no Brasil, é apontada por Dos Santos et al. (2019), como a grande responsável pelo primeiro contato dos estudantes com a prática de diferentes modalidades esportivas durante as aulas de EFE, nas quais se evidencia um espaço democrático de valiosas experiências cognitivas, motoras e sociais entre alunos. Por outro lado, So et al. (2018), lamentavelmente, evidenciam um envolvimento desfavorável das meninas na EFE, principalmente, quando o conteúdo ministrado se refere às AM\&EC.

Dois grandes obstáculos anunciados pelos professores de EFE no ensino da AM\&EC são o desenvolvimento da práxis e o envolvimento das meninas. É notório que as Lutas sempre foram vistas como atividades que oferecem riscos aos participantes e são contraindicadas para as meninas na EFE (Carvalho, 2019).

A investigação de Souza e Menezes (2019) realizada em duas escolas com meninas do sexto ano no ensino fundamental, revelou que $43 \%$ das entrevistadas afirmaram participar das aulas de EFE separadas dos meninos, seguindo a determinação da professora, com a prerrogativa de evitar a ocorrência de lesões. Quando foram questionadas sobre a vontade em participar de aulas mistas, $73 \%$ delas responderam que concordavam e tinham interesse.

Lima (2017) observou o comportamento de meninos em quadra, durante as aulas de EFE, e registrou algumas adversidades, com destaque para rejeição quanto a participação feminina nas atividades. Os meninos alegaram ainda que, elas atrapalhavam o jogo e podiam se machucar durante as aulas práticas de EFE. Percebemos nesses discursos a tentativa de subalternizar e depreciar a participação feminina no esporte, com argumentos encobertos de preconceito de gênero (Silva, 2017).

Entretanto, cabe aos professores tanto a discussão com os alunos sobre a desconstrução de processos discriminatórios, quanto a aplicação de atividades que tragam para a escola conteúdos interessantes que venham ser problematizados e questionados a partir da visão e do discurso dos alunos (Silva et al., 2020).

Seguindo este raciocínio, Lima et al. (2017) valorizam o debate das AM\&EC na EFE relacionando-as com a violência e questões de gênero no ambiente escolar, e justificam a importância desta interface como proposta de ensino dos valores culturais e de pacificação, utilizando todo potencial educativo embutido nos princípios filosóficos de diferentes modalidades como o Muay-Thai, Capoeira, Jiu-Jitsu, Taekwondo e Judô, mundialmente reconhecidas.

É possível perceber o quanto os alunos julgam sobre as divisões que existem nas aulas práticas de educação física. As meninas reclamam por não poderem participar e os meninos justificam a não participação das meninas, por ter em mente a concepção de que elas não possuem porte físico para a prática, que são fracas, que cansam rápidas, e elas não terem a capacidade para participarem. Outra explicação que limita a presença das mulheres considera o corpo como um recurso passivo, possuindo um horizonte orientado unicamente pela cultura (Santana da Silva, 2019).

Combater o olhar preconceituoso e excludente, e oportunizar a todos alunos, independente de raça, gênero ou condição física, o acesso à diversidade cultural e educacional é dever do professor. Recordamo-nos sempre de que o ser humano é construtor de ideias e culturas, e a nossa cultura corporal é um resultado das vivências dessas diferentes culturas (Lima et al., 2017).

Nesta perspectiva, os docentes de EFE, estão incumbidos de propagar a igualdade de direitos e deveres na sua atuação profissional utilizando de instrumentos pedagógicos pertinentes à realidade sociocultural e às necessidades regionais, no ensino 
de temas relevantes e diversificados que visam a construção de um ser humano autônomo, crítico e atuante na sociedade. Assim, a nova semântica das aulas de EFE, deve possibilitar a análise de práticas obsoletas que tornavam a aula excludente, e promover a quebra de paradigmas, excepcionalmente, quanto ao preconceito de gênero no ambiente educacional.

\section{Metodologia}

Esta investigação caracteriza-se por um Estudo de Caso (EC), por se tratar de um fenômeno que envolve processos sociais no contexto educacional. Pereira (2018, p. 70) afirma que EC é propício a quaisquer níveis e modalidades de ensino e pode abranger professor, aluno e turmas, com algum fenômeno em foco. Neste caso, o estudo será realizado com cinco turmas do ensino médio. O método qualitativo foi adotado para o estudo por favorecer a interpretação do fenômeno e possibilitar uma descrição e análise mais aprofundadas dos dados obtidos (Pereira, 2018, p. 66). O estudo tem caráter descritivo, pois revela detalhes dos fenômenos ocorridos nos dados coletados a partir da aplicação de inquérito por questionário, apontado por Gil (2008) como uma técnica padronizada de coleta de dados. Pereira $(2018$, p. 67) sugere a utilização do questionário pela viabilidade de agregar muitos participantes e por assegurar o anonimato das respostas, e afirma que a formulação de questões abertas permite aos envolvidos expressarem seus pensamentos acerca do assunto enriquecendo a investigação.

Esta pesquisa foi realizada no Centro Educacional Dom Ungarelli, município de Pinheiro-MA, com alunos do $3^{\circ}$ ano do ensino médio. A amostra foi por conveniência e contou com a participação voluntária de 150 estudantes, conforme mostra o fluxograma (Figura 1):

Figura 1 - Fluxograma amostral.

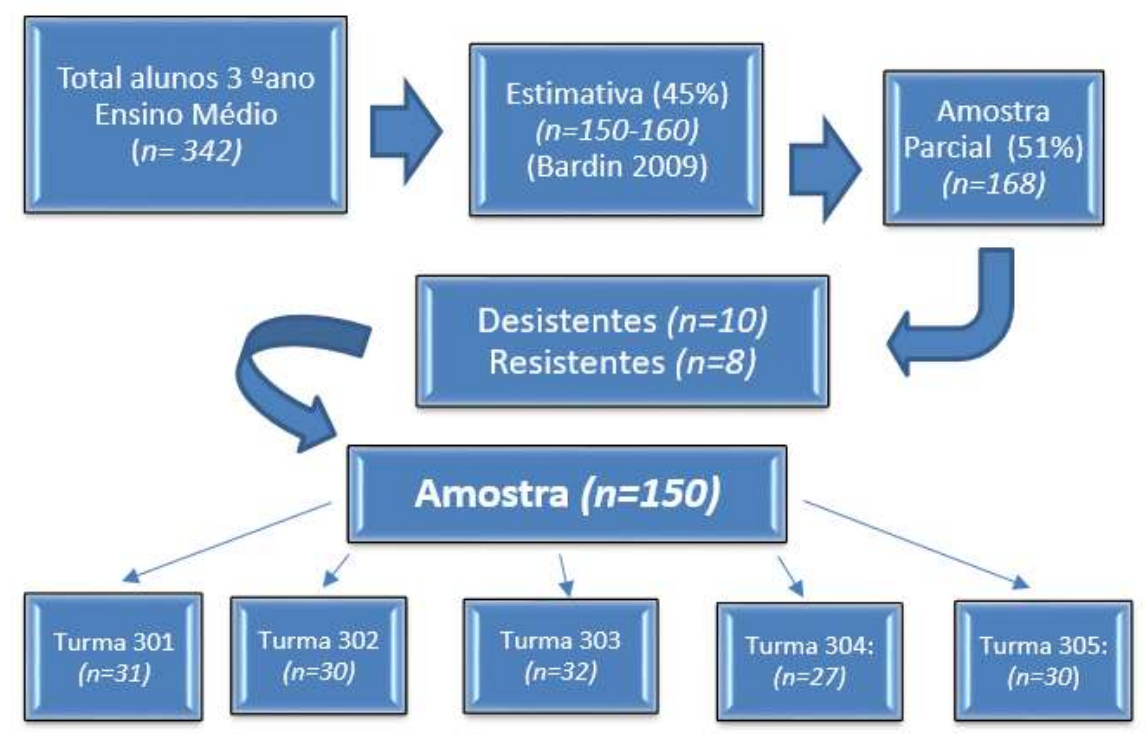

Fonte: Autores.

Os responsáveis pelos participantes, assinaram o Termo de Consentimento Livre e Esclarecido (TCLE) autorizandoos assim, a ingressar no estudo. No entanto, os alunos seriam excluídos do estudo caso a frequência nas aulas fosse inferior a 8 aulas, sendo que uma aula correspondeu a 50 minutos de teoria seguidos de mais 50 minutos de prática; ou caso o questionário não fosse respondido, antes ou após as intervenções. O estudo foi iniciado após autorização do Comitê de Ética em Pesquisa da Universidade Federal do Maranhão/UFMA, Campus Pinheiro, com o Parecer nº 3.212.643.

A respeito do perfil dos participantes, verificamos a idade, 100 deles (66,7\%) tinham 16 anos enquanto 50 (33,3\%) tinha 17 anos ou mais. Quanto à classificação por sexo, observou-se diferença mínima no quantitativo entre a participação 
masculina e feminina, contento respectivamente 83 (53\%) meninos e 67 (47\%) meninas.

Os alunos voluntários expuseram suas concepções acerca do preconceito de gênero quanto a participação das "meninas" durante as aulas de Lutas na EFE. Todos responderam a mesma pergunta, antes e após, participarem do bloco de 12 aulas, envolvendo 6 modalidades diferentes de Lutas, sendo uma teórica e outra prática, subsequente. Ambas com duração de 50 minutos cada, no período de 5 semanas. Foi questionado se a participação das meninas nas aulas de Lutas era um fator positivo ou negativo, e o porquê da resposta.

Para realizar as intervenções pedagógicas foram elaborados os planos de aula teórica contendo informações históricas, filosóficas e técnicas, além de vídeos e ilustrações sobre as seguintes modalidades: Huka-huka, Sumô, Judô, Jiu-Jitsu, GrecoRomana (Lutas de Agarre); Capoeira, Karatê, Taekwondo, Muay-Thai, Boxe (Lutas de Percussão/Toque); e Esgrima com Sabre, Florete e Espada (Lutas com Implemento), conforme classificação de Casado (1999). Nas aulas práticas, foram aplicados os Jogos de Combate, propostos por Santos (2012), como método didático de ensino, que contemplam jogos com objetivos e regras pré-estabelecidas, e envolvem movimentos característicos das AM\&EC e predominância da ludicidade.

Os dados obtidos foram planificados no Software Excel 2000 e analisados, estatisticamente, com o Software Statistical Package for the Social Sciences (SPSS), versão 24.0. Realizou-se a Análise de Conteúdo (AC), proposta por Bardin (2011), baseada na pré-análise, exploração do material e a interpretação dos dados.

Foi utilizado o teste do Qui-quadrado para identificar diferenças significativas entre os momentos pré e pósintervenção pedagógica. Foram avaliadas, quantitativamente, a associação existente entre as variáveis qualitativas, as frequências observadas e as frequências esperadas, sendo que, em todas as avaliações, foi considerado o Índice de Confiança $(\mathrm{IC})=95 \%,(\mathrm{p}=0.05)$.

\section{Resultados e Discussão}

Após realizadas as intervenções pedagógicas obtivemos resultados bastante expressivos acerca da interface entre o preconceito de gênero em referência a participação feminina nas aulas na EFE. Identificamos, no primeiro momento, a mudança na compreensão dos estudantes sobre a participação das meninas nas aulas de Lutas, como fator positivo ou negativo, conforme nos mostra o Gráfico 1:

Gráfico 1 - Percepção dos escolares sobre a participação das alunas nas aulas de lutas.

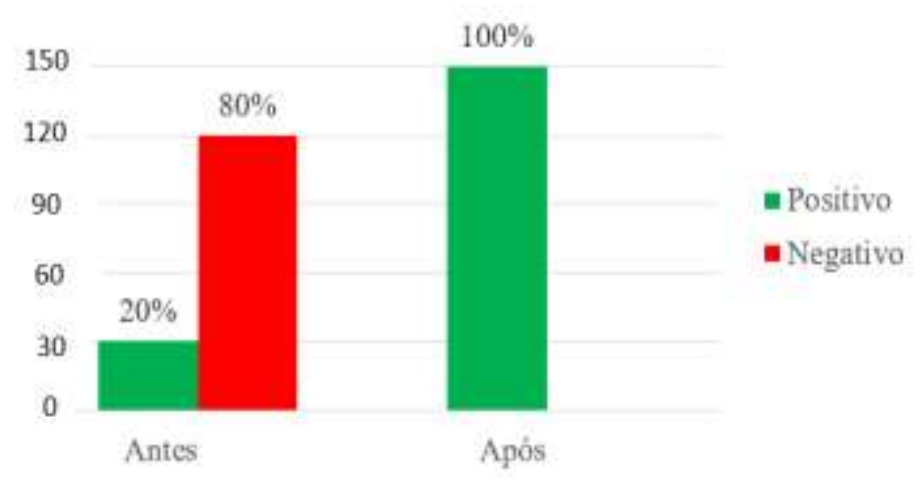

Fonte: Autores.

Evidenciamos, no momento anterior a intervenção pedagógica, que 120 (80\%) estudantes de ambos os sexos, apontavam como fator negativo, a participação das meninas nas aulas de Lutas; enquanto apenas 30 (20\%) alunos entendiam ser um ponto positivo a presença delas durante as aulas de Lutas na escola. Este olhar demasiadamente negativo e preconceituoso pode contribuir sobremaneira na inibição e no afastamento das alunas quando se trata deste conteúdo da 


\section{Educação Física.}

No estudo de Lima (2017) foi detectada grande resistência em relação a participação feminina nas aulas de Educação Física no ensino médio, envolvendo 29 discentes, sendo 15 meninas e 14 meninos, numa escola estadual, em Piritiba-BA. Ele revelou que $89,64 \%$ dos discentes avaliaram como negativa a presença ativa das meninas na quadra, enquanto apenas 10,34 avaliaram-na como positiva. Contudo, o conteúdo ministrado foi Futebol e o número de participantes foi consideravelmente inferior comparado ao presente estudo. No presente estudo, o número de participantes foi cinco vezes superior e a temática desenvolvida foi um conteúdo atual, inusitado e atraente.

Devemos salientar, no entanto, a transformação ocorrida no pensamento dos estudantes que passaram a compreender a presença das meninas nas aulas de Lutas como um fator extremamente positivo para todos os envolvidos. Este fato ficou comprovado ao verificarmos que todos os 150 alunos acolheram a presença feminina nas aulas de Lutas no ambiente educacional. Assim, destacamos a visão de So et al. (2018) que pregam a construção do conhecimento sobre Lutas, desarticulando-as de questões sexistas e visando o rompimento de estereótipos de gênero; e ainda sugerem ações com permutas constantes de duplas e participação simultânea dos envolvidos nas atividades com o propósito de diminuir a sensação de vigilância e julgamento dos demais, promovendo maior exploração dos jogos de oposição direta entre os oponentes.

Nesta acepção, este estudo corrobora integralmente, tanto no aspecto conceitual quanto na práxis, apresentada pelos autores supracitados, visto que, o mesmo infringe o preconceito de gênero ao proporcionar aos estudantes momentos de aprendizado significativo, com alto teor cultural e intercâmbio social. A execução do plano de aula elaborado a partir de uma proposta curricular, previamente estruturada, e posteriormente, contemplada nos livros didáticos se concretiza no denominado “Currículo em Ação", determinado por Sacristán (1998).

O segundo resultado obtido no estudo, enaltece de forma singular o potencial anti-sexista das Lutas em relação a atuação das meninas durante as aulas de Educação Física. A impressionante transformação no pensamento sexista e comportamento hostil dos estudantes nos remete à Sacristán (1998) que destaca o papel da educação como elemento de transformação do aprendiz, ou seja, o aluno processa as informações, adquire e assimila conhecimentos, os internaliza, e então, passa a analisar e compreender os fatos, discernindo-os, para posteriormente, elaborar suas próprias concepções e adotar nova postura diante da realidade que o cerca.

No Gráfico 2, enfatiza esta transformação do entendimento dos estudantes após vivenciarem as aulas teóricas e práticas sobre as AM\&EC na EFE. 
Gráfico 2 - Percepção dos estudantes quanto a participação feminina nas atividades de lutas na EFE, antes e após as práticas pedagógicas.

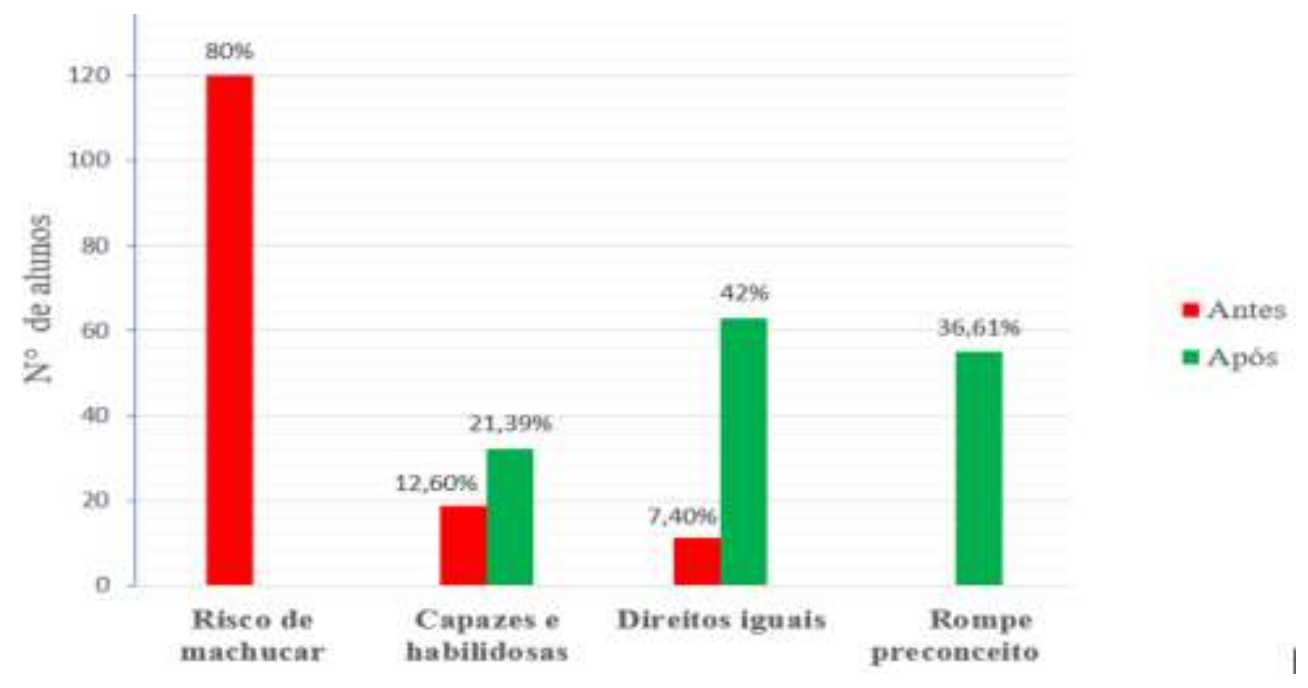

Fonte: Autores.

O "risco de machucar" foi apontado por $80 \%$ estudantes $(n=120)$, como o principal fator negativo relacionado a participação das meninas nas atividades de Lutas. Nota-se que há um explícito julgamento por parte dos estudantes nesta afirmativa, pois eles associam a resposta a uma suposta fragilidade e sensibilidade excessivas quanto a integridade física delas, conforme constatamos em alguns dos testemunhos recolhidos dos alunos: “[...] não é bom elas participar, elas podem se machucar” (A32); “[...] Isso não pode acontecer, elas são muito sensíveis” (A09).

Neste quesito encontramos fragmentos culturais e tradicionais que desfavorecem a inclusão das meninas nas aulas com o tema Lutas, revelando um alto grau de intolerância dos integrantes do estudo. Furlan e Santos (2008) afirmam que, desde o período de introdução dos esportes na EFE no Brasil, os meninos são reconhecidos pela força, hegemonia e poder, enquanto as meninas são enxergadas como vulneráveis, submissas e dóceis, ou seja, fisicamente inferiores quando comparada a eles.

Os resultados encontrados na presente investigação corroboram com aqueles obtidos na pesquisa de So et al.(2018), os quais pretendiam analisar a mobilização das meninas do $7^{\circ}$ ano do ensino fundamental, com o conteúdo Lutas, numa escola municipal, na periferia de Bauru (SP), os resultados apontaram que o medo de se machucar como um fator limitante da participação feminina, além de revelar uma prática pedagógica docente que reforça a distinção entre meninos e meninas, e utiliza conceitos e tradições que valorizam o corpo padronizado, fortalecendo atitudes preconceituosas.

O "medo de se machucar" foi confirmado no estudo de Lima (2017) com entrevistas a adolescentes cuja maioria afirmou não gostar das aulas de Lutas, devido à inferioridade da competência atlética delas quando comparada aos adolescentes do sexo masculino.

Na pesquisa etnográfica de Uchoga e Altmann (2016), que objetivou entender como se dão as relações de gênero nos diferentes blocos de conteúdo de EFE, realizado em duas escolas estaduais, do município de Campinas (SP), constatou-se que, professores de Educação Física, diretores da escola e pais, reforçam preconceitos de gênero clássicos, quando justificam a ausência das meninas nas aulas, com o discurso do "medo de se machucar", embora não utilizem este argumento para os meninos.

A grande maioria dos professores de EFE se prendem nessa prerrogativa para justificar a ausência das AM\&EC em suas aulas; sendo que, neste cenário deveria prevalecer o compromisso do professor no trato pedagógico do eixo temático AM\&EC no exercício profissional, explorando potencial educativo deste conteúdo em prol da formação integral do aluno 
(Miranda \& Dos Reis, 2020).

No que se refere às capacidades e habilidades exigidas durante a execução das ações peculiares às Lutas, observadas na segunda resposta no gráfico, verificamos mudanças significativas. Os estudantes subestimaram o acervo motor e o potencial cognitivo das meninas sem se quer, conhecerem ou terem vivenciado alguma das atividades propostas no estudo. Apenas 19 $(12,6 \%)$ alunos acreditavam que as meninas eram capazes e habilidosas o suficiente para participaram das tarefas propostas, conforme esclarecem as respostas: "[...] elas não vão conseguir fazer, elas são fracas e só atrapalham” (A10); “[...] elas não sabem jogar nada, ainda mais lutar, aí que não sabem mesmo” [...](A144); “[...] eu só joguei queimado e nunca lutei, acho que não dou conta." (A83); "As mulheres tem um temperamento muito forte, e já pensou uma mulher brava e que saiba lutar. Sou contra." (A70).

A seletividade é uma das maiores mazelas introduzidas nas aulas de EFE (Rizzo, 2017). Lima (2017) assegura que, quando se trata de Lutas na EFE, as meninas são abolidas da prática não apenas pelo fato de serem mulheres, mas pelo nível de habilidade e a fragilidade delas serem equiparadas as do gênero masculino. Para Furlan e Santos (2008) os meninos, durante a prática esportiva, se reconhecem como superiores as meninas, presumidamente pelas chances que lhes são concedidas, e a elas, limitadas.

Entretanto, após conhecerem, na teoria, ações específicas de algumas modalidades de AM\&EC e executarem as tarefas lúdicas e bem simples com confronto direto entre dois oponentes, os estudantes perceberam que a "proposta de lutar" era divertida, interessante e não exigia um domínio de técnicas específicas de alguma AM\&EC; mas requeriam sim, alta demanda de concentração, percepção e tomada de decisões simultâneas e constantes dos envolvidos no embate.

De forma formidável, os estudantes transpuseram esta barreira do prejulgamento e se entregaram, cada vez mais, às Lutas, na medida em que se avançava a programação. Foi registrado, ao final do estudo, que praticamente o dobro de estudantes $(21,39 \%)$ passaram a compreender que a capacidade e habilidade das meninas de participar das aulas de Lutas são compatíveis com as dos meninos, e não estão vinculadas ao gênero. Inclusive, vários meninos apresentaram limitações na motricidade e lentidão nas tomadas de decisões durante os confrontos, por não terem vivenciados experiências semelhantes, nas aulas de EFE.

Inúmeras habilidades podem ser adquiridas por meio da prática e aperfeiçoadas à medida em que aluno pratica e entende o porquê dessa prática. Assim, os docentes são os protagonistas em oferecer oportunidades de práticas diferenciadas a todos os alunos. Neste aspecto, Souza Souza Júnior e Darido (2002), consideram fundamental o desempenho do professor de EFE em fomentar a formação cidadã, proporcionando as mesmas oportunidades de aprendizado e vivências motoras a todos os alunos, independente do gênero.

Outrossim, destacamos as opiniões de alguns integrantes do estudo acerca desta questão: [...] "É muito importante que o sexo feminino mostre que não é um sexo frágil, e tem tanta capacidade quanto os meninos, de ter um bom desenvolvimento" (A40); [...] "elas pareciam fracas, que não tinham força, mas lutei com uma e foi difícil demais, mas ganhei” [...] (A68); [...] “teve um menino que quase perdeu pra elas, mas o tempo acabou”[...] (A122); [...] "elas tem que participar sim, muitas delas são mais habilidosas que eu" (A09).

O resultado mais substancial e de maior significância estatística está vinculado aos "direitos iguais” de participação entre pessoas de diferentes gêneros. A discrepância entre os resultados encontrados foi gigantesca. Se antes das intervenções, 7,4\% dos alunos (n=10) afirmavam que todos tinham o mesmo direito de participar das aulas de Lutas; ao término da programação, constatou-se um aumento exorbitante, seis vezes maior, com $42 \%$ dos estudantes (n=60) se manifestando em favor da condição de igualdade de direitos de participação naquele contexto educacional.

Sublinhamos aqui, alguns trechos escritos pelos estudantes no pós-intervenção, revelando seus pensamentos sobre a questão de igualdade de direitos: “[...] porque as meninas têm os mesmos direitos que os meninos.” (A55); “[...] mostrou que 
nas lutas todos somos iguais, independente do gênero, todos somos iguais.” (A70). “[...] todos tem que participar, a aula é para nós e para as meninas também” (A92); “[...] Todos somos iguais, hoje em dia as mulheres também têm o conhecimento sobre as lutas" (A141).

Os apontamentos supracitados vão ao encontro com o pensamento de Silva et al. (2020) ao ratificar as Lutas enquanto componente curricular fundamental no processo de eliminação de estereótipos e de promoção da igualdade de direitos nas aulas de EFE. Santos et al. (2019) declaram a participação das meninas nas aulas de Lutas, como fator confrontante à ideia de preconceito de gênero e contribui para a emancipação feminina na construção e ampliação do seu espaço na sociedade, diminuindo a desigualdade de gênero e garantindo o direito de oportunidades a todos (Santos et al., 2019).

Para Reis e Eggert (2017), a Educação é um direito de todos sem subdivisões por orientação sexual ou identidade de gênero, e reforça o papel dos Estados no papel de oferecer acesso igualitário à Educação e tratamento igual, desenvolvendo assim, o respeito aos direitos humanos, proteção adequada contra exclusão, violência e discriminação. Todos têm o direito de viver experiências motrizes, "se movimento logo existo" (Lima et al., 2017, p.441).

Corroborando com esta acepção, Coledam et al. (2014) destacam a relevância da educação conjunta, entre meninos e meninas, com direito e igualdade de oportunidades entre os gêneros, independente do conteúdo e atividade proposta. No presente estudo identificamos que as AM\&EC favorecem o contato entre os estudantes, dentro de um contexto de regras acordadas entre os participantes e o professor, e possibilita ainda, não só a participação feminina, mas a interação dos gêneros de maneira respeitosa e consciente, mesmo no confronto direto entre eles: menina versus menino.

Do resultado crucial da investigação emanou uma nova consciência consolidada pelos estudantes com referência às Lutas no campo educacional. A concepção formada por eles após as intervenções pedagógicas elucida e robustece as AM\&EC como um elemento indispensável na educação, pois 55 (36,61\%) estudantes passaram a compreender e valorizar a essência das Lutas, por meio dos princípios filosóficos e os valores pessoais agregados à prática de diversificadas modalidades, como uma ferramenta que contribui substancialmente no combate ao preconceito de gênero, ao afirmarem que as Lutas, literalmente, "rompem preconceitos".

Destacamos esta emancipação intelectual ao revelarmos os dizeres alguns discentes: “[...] Chega dessa história que lutar é coisa de menino e não de menina, chega desse pensamento machista” (A22); “[...] pois mostra que não há espaços para machismo na educação física e que alguns paradigmas estão sendo quebrados” (A62); “[...] elas são mais interessadas que os meninos (A88)”; “[...] Fomos incluídas” (A05); “[...] foi bom para eles verem que tem meninas que conseguem lutar”

Romper preconceitos é sinônimo de inclusão. Incluir significa a reestruturação das culturas, políticas, e principalmente, da prática escolar e docente, muitas vezes elitista e excludente. A luta contra ações sexistas nas aulas de EFE se concretiza a partir de uma perseverança de ações de inclusão percebidas e internalizadas pelos estudantes no ambiente escolar e na contextualização de cada temática desenvolvida na aula, propriamente dita (Carvalho, 2019; Silva et al., 2020).

A inclusão social através do desporto remete para o desenvolvimento de competências pessoais, sociais, motoras ou outras, em que as boas práticas se dirigem à promoção do desporto formativo e privilegia os princípios éticos do desporto e valores associados junto de crianças e jovens em meio escolar (Marivoet, 2014).

Certificamos, neste estudo, uma expansão e um fortalecimento das relações sociais entre os alunos, principalmente, os de gêneros distintos. O método adotado durante as aulas de Lutas favoreceu o intercâmbio entre os participantes, pois havia a necessidade de alternar os componentes a cada confronto, e não era permitido manter a disputa com o mesmo adversário; impelindo-os a se inter-relacionar, fomentando a construção das redes de sociabilidade.

O estudo de Marivoet (2010) corrobora com os achados da atual investigação, pois ressalta o papel do esporte como instrumento que vem agregar inúmeras formas de culturas e com grande potencial de aproximação das pessoas. Esta aproximação leva o indivíduo a socialização, ou seja, a inclusão, e a pessoa constrói uma base de respeito, interação, igualdade, 
aprendizagem.

Tais princípios/valores apreendidos no ambiente de ensino eram replicados em outros espaços sociais, pois, a estruturação destes valores decorre das relações que se estabelecem ao nível dos valores presentes nos diferentes espaços sociais, em especial, a "família, os amigos e o clube" desportivo, tendo presente as sociabilidades aí dinamizadas" (Marivoet, 1997, p. 106).

Os estudantes, apesar de se encontrem no mesmo ambiente durante um período considerado suficiente para se socializarem e estabelecerem maior aproximação, tal fato não ocorre, pois são formados vários subgrupos na turma. Em contrapartida, as ações executadas nas aulas de Lutas proporcionaram aos alunos momentos peculiares de inter-relação pessoal, até então, nunca vivenciados.

Nesta perspectiva, Brás (2010) ressalta que o corpo é o instrumento principal dessa cultura de combate durante as aulas de Educação Física e serve como produto social neste contexto de socialização, e afirma que "o corpo enquanto produto social tem necessariamente que ser situado no tempo e no espaço, pois estes condicionam a percepção que se tem acerca dele. É na sociedade que nós buscamos as nossas ideias, é a partir daí que nós criamos o nosso organismo mental” (Brás, 2010, p.3).

Bourdieu (1980) identificou as redes de relações sociais entre indivíduos do mesmo grupo, bem como, a quantidade e a qualidade de desses relacionamentos e verificou que, as relações estabelecidas entre os indivíduos pertencentes a um determinado grupo não advêm apenas da partilha das relações objetivas ou do mesmo espaço socioeconómico, mas também das trocas materiais e simbólicas, cuja instauração e perpetuação pressupõe o reconhecimento dessa proximidade.

Diante deste fato, nos remetemos à Sacristán (1998), por acreditar que todo aprendizado adquirido na escola tem a função imprescindível de perpetuar no âmbito social, o qual abrande a família e a sociedade, concretizando, dessa forma, a aprendizagem significativa, caracterizada pelo autor como a aprendizagem que agrega valores e envolve sentimentos que serão repassados em diferentes contextos educacionais formais e informais.

\section{Conclusão}

Com base neste estudo de caso, é possível concluir que existe a latência do preconceito direcionado a mulheres/discentes, arraigado por questões históricas, culturais, sociais e legislativas que marcaram épocas. Considerando os resultados apresentados, conclui-se que o conteúdo Lutas pode ser uma importante ferramenta educacional no combate aos estereótipos e preconceitos, reafirmando a necessidade de defender uma educação voltada ao respeito às diferenças, nomeadamente na EFE, e consequentemente "lutar" para/pela promoção da dignidade da pessoa humana. Os resultados mais expressivos deste estudo evidenciam que, no período anterior a intervenção os discentes tinham a percepção negativa quanto a participação das meninas nas aulas de Lutas, bem como grande maioria associava este conteúdo ao risco das meninas se machucar. Entretanto, após a intervenção os discentes passaram a veiculá-lo, a uma prática onde ambos os gêneros têm diretos iguais, além de associarem a um instrumento capaz de romper preconceitos e estereótipos, como pode ser observado nos argumentos dos discentes.

Entendemos que houve algumas limitações na pesquisa como a ausência da descrição rigorosa das aulas ministradas e a composição amostral abraçar somente os alunos no último ano do ensino médio.

Entretanto, sugerimos que novas investigações sobre a unidade temática Lutas, no âmbito educacional, precisam se concretizar, tendo em vista o ensino básico no geral, com o propósito de quebrar paradigmas acerca das Lutas e com intuito de propagar seu potencial educativo. 


\section{Referências}

Alves, T. E. K. (2019). Entre espadas, floretes e sabres: uma história da civilização dos costumes na esgrima [Dissertação de Mestrado, Universidade Federal do Paraná].

Bardin, L. (2011). Análise de Conteúdo (70a ed.), Almedina Brasil.

Beauvoir, S (1980). O segundo Sexo: Fatos e Mitos: Ed. Nova Fronteira.

Bourdieu, P. (1980). Le capital social: notes provisoires. Actes de la recherche en sciences sociales, 31(1), 2-3.

Brás, J. G. V. (2010). Corpo, sociedade e escola: sensibilidade educativa. Entretextos (20).

Camargo, W. X., \& Kessler, C. S. (2017). Além do masculino/feminino: gênero, sexualidade, tecnologia e performance no esporte sob perspectiva crítica. Horizontes Antropológicos, 47, 191-225.

Cardoso, B. L. C., Cárdenas, C. J., \& Sampaio, T. M. V. (2013). Limites e preconceitos em modalidades hegemonicamente masculinas: o caso do boxe feminino. In XVIII Congresso Brasileiro de Ciências do Esporte (Vol. 18). Anais do V Congresso Internacional de Ciências do Esporte.

Carvalho, R. S. (2019). Lutas, um Conteúdo para Educação Física Escolar: contribuições e perspectivas. [Trabalho de Conclusão de Curso, Faculdade Pitágoras de São Luís].

Casado, J. E. (1999). Aproximación histórico-conceptual a los deportes de lucha. In Introducción al judo (pp. 23-54). Editorial Hispano Europea.

COI. (2016). Comitê Olímpico Internacional. Women In The Olympic Movement. https://stillmed.olympic.org/Docu ments/Reference_documents_Factsheets/Women_in_Olympic_Movement.pdf.

Coledam, D. H. C., Ferraiol, P. F., Pires Junior, R., dos-Santos, J. W., \& Oliveira, A. R. D. (2014). Prática esportiva e participação nas aulas de educação física: fatores associados em estudantes de Londrina, Paraná, Brasil. Cadernos de Saúde Pública, 30, 533-545.

Conselho Nacional de Desportos. (1965). Deliberação n $n^{\circ} 7-65$, de 2 de agosto. Baixa instruções às entidades desportivas do país sobre a prática de desporto pelas mulheres. http://cev.org.br/biblioteca/deliberacao-n-7-2-agosto-1965/.

Costa, R. R. (2019). Pânico Moral e a Abordagem de Gênero nas Escolas. Cadernos de Gênero e Diversidade, 5(3), 53 -66.

Da Silva Barros, P., \& Queiroz, G. R. P. C (2020). O saber docente em tempos de ascensão do neoconservadorismo: como professores abordam gênero e sexualidade nas aulas de Ciências. Research, Society and Development, 9(8), e401985429-e401985429.

Souza, F. S. Da., \& Menezes, N. M. S. (2019). “Só porque sou menina, não posso?”: o lugar do feminino nas aulas de Educação Física. Anais da Jornada de Educação Física do Estado de Goiás (ISSN 2675-2050), 1(2), 159-162.

Decreto-lei n 89.406, de 20 de março de 1984. (1984). Conselho Nacional De Justiça baixa instruções às Entidades Desportivas do País, para a prática de desportos pelas mulheres. Legislação Sobre Esportes. Diário Oficial da União. Brasília.

Decreto-lei nº 3.199, de 14 de abril de 1941. (1941). Estabelece as bases de organização dos desportos em todo o país. Diário Oficial da União, Rio de Janeiro.

Do Prado, V. M., Altmann, H., \& Ribeiro, A. I. M. (2016). Condutas Naturalizadas na Educação Física: uma questão de gênero?. Currículo Sem Fronteiras. 16(1), 59-77.

Dos Santos, J. B., Serra, H., \& de Souza Pereira, A. (2019). Compreensão de estudantes do ensino médio sobre sedentarismo, nível de atividade física e exposição a comportamentos sedentários. Revista Thema, 16(4), 818-831.

Felipe, J. (2000). Infância, gênero e sexualidade. Educação \& Realidade, 25(1).

Fernandes, V., Mourão, L., Goellner, S. V., \& Grespan, C. L. (2015). Mulheres em combate: representações de feminilidades em lutadoras de Boxe e MMA. Revista da Educação Física/UEM, 26(3), 367-376.

Ferreira, T. J. (2016). A capoeira sob a ótica de gênero: o espaço de luta das mulheres nos grupos de capoeira. [Dissertação de Mestrado, Pontifícia Universidade Católica de Goiás].

Firmino, C. B. (2014). 'Sou atleta, sou mulher': a representação feminina sob análise das modalidades mais noticiadas nas olimpíadas de Londres 2012. [Dissertação de Mestrado, Universidade Estadual Paulista de Bauru].

Firmino, C. B., \& de Souza Ventura, M. (2017). A evolução histórica da participação feminina nos Jogos Olímpicos da Era Moderna e a inclusão das mulheres no esporte de competição. Tríade: Revista de Comunicação, Cultura e Mídia, 5(10).

Furlan, C. C., \& dos Santos, P. L. (2008). Futebol feminino e as barreiras do sexismo nas escolas: reflexões acerca da invisibilidade. Motrivivência, (30), 2843.

Gil, A. C. (2008). Como elaborar projetos de pesquisa. (4a. ed.), Atlas.

Jardim, J. G. (2018). "It's time"! MMA feminino, mercado da beleza e cis-heteronormatividade: uma etnografia multissituada com lutadoras brasileiras. [Tese de Doutorado, Universidade Estadual Paulista de Marilia].

Ledur, J. A., Assmann, A. B., \& Mazo, J. Z. (2018). Sumô: esporte de japonês em Ivoti/RS. Motrivivência, 30(56), 120-139. 
Leite, D., Souza, S., \& Pereira, B. (2017). Ser professor de educação física! Mais pedagogia ou empatia? In J. A. F. P. Junior (Org.), Conhecimentos do professor de educação física escolar (pp. 243-271). EdUECE.

Lima, D. R. (2017). A participação feminina no futebol nas aulas de Educação Física Escolar: Por quê não? [Trabalho de conclusão de curso, Universidade de Brasília].

Lima, K. E. S., de Medeiros Lima, L. C., \& de Almeida, M. T. P. (2017) As lutas, artes marciais e esportes de combate, como conteúdo curricular e educativo nas aulas de educação física. In J. A. F. P. Junior (Org.), Conhecimentos do professor de educação física escolar (pp. 422-442). EdUECE.

Lins, B. A., Machado, B. F., \& Escoural, M. (2016). Diferentes, não desiguais. Revista Volta, 20(2), 305-309.

Louro, G. L. (2018). Um corpo estranho: ensaios sobre sexualidade e teoria quer. Autêntica.

Marivoet, S. (1997). Dinâmicas sociais nos envolvimentos desportivos. Sociologia - Problemas e Práticas (23), 101-113.

Marivoet, S. (2010). Sociological Approach on Sports Ethics in a Context of Social Change. Physical Culture and Sport. Studies and Research, XLIX, 39-52.

Marivoet, S. (2014). Inclusão Social no Desporto. Contributos para uma nova área de investigação. In: VIII Congresso Português de Sociologia, 40 anos de democracia(s): progressos, contradições e prospetivas. Évora; UE.

Ministério da Educação. (2015). Base Nacional Comum Curricular. Brasília, http://basenacionalcomum.mec.gov.br/\#/site/conhecaDisciplina?disciplina

Miragaya, A. (2007). As mulheres nos Jogos Olímpicos: participação e inclusão social.

Rubio, K. (2018). O legado heroico do papel social do atleta. In: Da Costa, L. P., Corrêa, D., Villano, E. R. B., \& Miragaya, A. (Orgs.) Legados e Mega eventos esportivos. Ministério do Esporte, Brasília. 217-226.

Miranda, A. L. F., \& dos Reis, L. M. C. (2020). O conteúdo lutas nas aulas de Educação Física nas escolas de ensino fundamental do município de São Miguel do Guamá-PA: Revista de Estudo e Pesquisa em Educação, 22(1), 120-136.

Mourão L., \& Sebastião, V. (2005) Esporte e inclusão social - mulheres. In: Da Costa, L. P. (Org.) Atlas do esporte no Brasil. Atlas do esporte, educação física e atividades físicas e saúde e lazer no Brasil. 613-614.

Oliveira, F. P. (2011). Inserção da mulher no ambiente desportivo. Arquivos em Movimento, 2(1), 114-122.

Oliveira, J. P. D., \& Leal, L. A. P. (2009). Capoeira, identidade e gênero: ensaios sobre a história social da capoeira no Brasil. Editora Da Universidade Federal Da Bahia.

Pereira, F. C. D. R., \& Carneiro, F. F. B. (2016). Análise bibliográfica sobre a luta esportiva: gênero e motivação no taekwondo feminino. Revista Mineira de Educação Física, 24(2), 103-114.

Reis, T., \& Eggert, E. (2017). Ideologia de gênero: uma falácia construída sobre os planos de educação brasileiros. Educação \& Sociedade, 38(138), 9-26.

Rizzo, D. (2017). Esporte para todos ou quase todos? considerações sobre a prática esportiva educacional (1nd ed.). Editora das Faculdades Magsul EdFAMAG.

Rodrigues, A. I. C., Baião Junior, A. A., Antunes, M. M., \& Almeida, J. J. G. D. (2017). The perception of school directors in the city of Jaguariúna about combat sports. Journal of Physical Education, 28.

Rosa, M. V., de Oliveira Souza, M., \& Borges, A. M. (2020). Preconceito contra a mulher na educação física escolar no nono ano. Revista Prâksis, 1, 102-117.

Rubio, K., \& Simões, A. C. (1999). De espectadoras a protagonistas-A conquista do espaço esportivo pelas mulheres. Movimento (ESEFID/UFRGS), 5(11), $50-56$.

Sacristán, J. G. (1998). O currículo: os conteúdos do ensino ou uma análise prática. Compreender e transformar o ensino, 4, 119-148.

Santana da Silva, G. O. (2019). As mulheres atletas de Mixed Martial Arts: Uma perspectiva de gênero. [Tese de Doutorado, Universidade do Porto].

Santos, F. M. B., Cardoso, G. E., \& Sousa, F.E.V.S. (2019). Questões de gênero nas aulas de educação física: um bate-papo sobre o assunto com discentes do ensino médio de uma escola pública do município de Pedreiras-MA. In F. E. V. de. Souza (Org.), Reflexões sobre as questões de gênero nas aulas de Educação Física. 25-62. Pimenta Cultural.

Santos, S. L. C. D. (2012). Jogos de Oposição: ensino de Lutas na escola: Phorte Editora SA.

Silva, F. E. L., Mariano, E. R., Souza, S., Filho, S. O., \& Rizzo, D. T. de S. (2020). Ressignificação das lutas na concepção de estudantes do ensino médio. 19(01), 101-109.

Silva, H. V. A. D., Nascimento, T. A. D., Lima, T. M. D., \& Costa, A. D. S. (2019). The effect of an initiation to struggles structured program on the physical capacities, visual attention and school performance in elementary school children. Revista Brasileira de Ciências do Esporte, 41(2), 176-182.

Silva, J. D. (2017). Futebol de mulheres em Erechim: um estudo sobre (in) visibilidade e os limites da profissionalização. [Trabalho de Conclusão de Curso, Universidade federal da Fronteira do Sul].

Silveira, V. T., \& Vaz, A. F. (2016). Corpo feminino no esporte: entre heterossexualidade compulsória e lesbofobia. Revista Brasileira de Ciências do Esporte, $36(2), 212-222$.

So, M. R., Martins, M. Z., \& Betti, M. (2018). As relações das meninas com os saberes das lutas nas aulas de Educação Física. Motrivivência, 30(56), 29-48. 
Research, Society and Development, v. 10, n. 3, e4410312946, 2021

(CC BY 4.0) | ISSN 2525-3409 | DOI: http://dx.doi.org/10.33448/rsd-v10i3.12946

Souza Júnior, O. M., \& Darido, S. C. (2002). A prática do Futebol feminino no ensino fundamental. Motriz, 8(1), 1-9.

Terret, T. (2006). Le genre dans l'histoire du sport. Clio. Femmes, Genre, Histoire, 23, 1-21.

Uchoga, L. A. R., \& Altmann, H. (2016). Educação física escolar e relações de gênero: diferentes modos de participar e arriscar-se nos conteúdos de aula. Revista Brasileira de Ciências do Esporte, 38(2), 163-170. 